\title{
BMJ Restless legs syndrome and risk of Open incident cardiovascular disease in women and men: prospective cohort study
}

\author{
Anke C Winter, ${ }^{1}$ Markus Schürks, ${ }^{1,2}$ Robert J Glynn, ${ }^{1}$ Julie E Buring, ${ }^{1}$ \\ J Michael Gaziano, ${ }^{1}$ Klaus Berger, ${ }^{3}$ Tobias Kurth ${ }^{1,4,5}$
}

To cite: Winter AC, Schürks M, Glynn RJ, et al. Restless legs syndrome and risk of incident cardiovascular disease in women and men: prospective cohort study. BMJ Open 2012;2:e000866. doi:10.1136/

bmjopen-2012-000866

- Prepublication history for this paper is available online. To view these files please visit the journal online (http:// dx.doi.org/10.1136/

bmjopen-2012-000866).

For author footnote see end of the article.

Received 10 February 2012 Accepted 16 February 2012

This final article is available for use under the terms of the Creative Commons Attribution Non-Commercial 2.0 Licence; see http://bmjopen.bmj.com

For numbered affiliations see end of article.

Correspondence to Dr Tobias Kurth; tobias. kurth@univ-bordeaux.fr

\section{ABSTRACT}

Objectives: To evaluate the association between restless legs syndrome (RLS) and incident cardiovascular disease (CVD).

Design: Prospective cohort study.

Setting: Women's Health Study (WHS) and Physicians' Health Study (PHS), USA.

Participants: 29756 female health professionals aged $\geq 45$ years and 19182 male physicians aged $\geq 40$ years at baseline.

Main outcome measures: Main outcome was incidence of major CVD; secondary outcomes were first incidence of myocardial infarction, stroke, death due to CVD or coronary revascularisation.

Results: 3487 (11.7\%) women and 1373 (7.2\%) men met International Restless Legs Study Group criteria for RLS. In the WHS 450 major CVD events occurred and 1064 major CVD events were confirmed in the PHS. In both cohorts, RLS was not associated with increased risk of major CVD, stroke, myocardial infarction, CVD death or coronary revascularisation. After adjustment for major vascular risk factors, the HRs $(95 \% \mathrm{Cl})$ for major CVD were 1.15 (0.88 to 1.50$)$ in women and 1.01 (0.81 to 1.25$)$ in men. Highest multivariable-adjusted HRs were 1.29 (0.91 to 1.82) for total stroke in women and 1.22 (0.87 to 1.70$)$ for CVD death in men. Excluding participants with comorbidities potentially leading to RLS did not substantially change the effect estimates.

Conclusions: In these large prospective studies of female and male health professionals, RLS was not associated with an increased risk of any incident CVD event. The data do not support the hypothesis that RLS is a marker of increased risk of vascular disease.

\section{INTRODUCTION}

Restless legs syndrome (RLS) is a movement disorder characterised by an urge to move the legs, typically during rest, and is mostly accompanied by unpleasant leg sensations. This syndrome has been increasingly studied over the last years. According to results from

\section{ARTICLE SUMMARY}

Article focus

- The aim of this study is to evaluate the association between RLS and incident cardiovascular events in two large prospective cohort studies.

\section{Key messages}

- The results of our two large prospective cohorts do not suggest that either women or men suffering from RLS are at increased risk for any vascular disease event.

- RLS should not be considered a marker for increased CVD risk.

Strengths and limitations of this study

- Strengths of this study include the large number of participants and outcome events, the prospective study design, the standardised assessment of RLS according to the four minimal diagnostic criteria and confirmation of CVD cases by medical record review.

- The following limitations should be considered: the information on RLS was self-reported and misclassification of cases is possible. No information on frequency, severity and duration of RLS symptoms was available and both cohorts consist of white health professionals, which may limit the generalisability of the results to other populations.

population-based studies, RLS is a common disease with an estimated prevalence ranging from $4 \%$ to $29 \% .^{12}$ The prevalence of RLS increases with age, and women are predominately affected. There is increasing evidence that dysfunction of the dopaminergic system is one underlying cause for the syndrome, ${ }^{3}$ although the precise mechanisms of this disease are still unknown. In addition, results from genetic studies indicate a genetic predisposition for the disorder. ${ }^{4}$

Different comorbidities have been reported to be associated with RLS. Particularly, the 
relationship between RLS and prevalent cardiovascular disease (CVD), as suggested by several cross-sectional studies, ${ }^{6-12}$ has gained attention due to the high prevalence of both conditions in the general population. In addition, one prospective study from the UK has reported an association between RLS and incident stroke, which was not found for ischaemic heart disease. ${ }^{13}$ As potential mechanisms for this relationship, an unfavourable CVD risk factor profile and an elevated activity of the sympathetic nervous system resulting in tachycardia and hypertension have been proposed. ${ }^{14}{ }^{15}$ However, data on the association between RLS and vascular risk factors are inconsistent and studies evaluating the association between RLS and incident CVD are lacking.

Evaluating the association between RLS and CVD is of substantial public health importance because of the high prevalence of RLS. In addition, a relationship between these two diseases would have clinical implications for the management and treatment of patients and would further stimulate research to identify potential common pathophysiological mechanisms. The cross-sectional design of previous studies, however, does not allow determining the direction of association between RLS and CVD and prospective data are lacking. We therefore sought to evaluate the association between RLS and risk of incident CVD in two large prospective cohort studies, the Women's Health Study (WHS) and the Physicians' Health Study (PHS).

\section{METHODS}

Study populations

The design and methods of both cohorts have been described in detail previously. ${ }^{16-19}$ Briefly, the WHS was a randomised placebo-controlled trial designed to test the risks and benefits of low-dose aspirin and vitamin $\mathrm{E}$ in the primary prevention of CVD and cancer among apparently healthy women. A total of 39876 US female healthcare professionals aged 45 years or older at study entry (1992-1995) without a history of CVD, cancer or other major illnesses were randomly assigned to receive active aspirin (100 $\mathrm{mg}$ on alternate days), active vitamin $\mathrm{E}$ (600 IU on alternate days), both active agents or both placebos. Baseline information was self-reported and collected by a mailed questionnaire that asked about many cardiovascular risk factors and lifestyle variables. Twice in the first year and yearly thereafter, participants were sent follow-up questionnaires asking about study outcomes and other information during the study period. After the termination of the trial in March 2004, the women who were still alive and willing to participate entered an observational follow-up. The return date of the 108-month questionnaire containing questions on RLS was defined as new baseline for this analysis. Of the 33092 women in active follow-up at 108 months, we excluded 1722 women with missing RLS information, 1614 women who reported CVD events (myocardial infarction, stroke, CVD death, coronary revascularisation) and angina prior to receiving the 108-months questionnaire, leaving a total of 29756 women free of CVD or angina for this analysis.

The Physicians' Health Study I (PHS I) was a randomised, double-blind placebo-controlled trial to test the benefits and risks of low-dose aspirin $(325 \mathrm{mg}$ ) and $\beta$-carotene $(50 \mathrm{mg})$ in the primary prevention of CVD and cancer among 22071 apparently healthy physicians aged 40-84 years at baseline in 1982. Baseline information was self-reported and collected by means of a mailed questionnaire that asked about many cardiovascular risk factors and lifestyle variables. Every 6 months in the first year and yearly thereafter, follow-up questionnaires were sent to the participants. Since the trials' termination in 1995, the men are continued to be followed either on an observational basis or as part of the Physician's Health Study II (PHS II).

The PHS II was launched in 1997. The PHS II is an ongoing randomised, double-blind placebo-controlled trial to test the effects of vitamin $\mathrm{C}(500 \mathrm{mg})$, vitamin $\mathrm{E}$ (400 IU), $\beta$-carotene $(50 \mathrm{mg})$ and a daily multivitamin (Centrum Silver) in the prevention of total and prostate cancer, CVD and age-related eye disease among 14641 US male physicians aged 55 years and older, including a total of 7,641 PHS I participants who were willing and eligible to enter the PHS II. Baseline information was selfreported, and follow-up information was collected annually by mailed questionnaires. For the purpose of this analysis, we pooled data from the PHS I and PHS II, yielding a total of 29071 participants. The return date of the questionnaire containing the RLS question (216month questionnaire for PHS I participants and 12month questionnaire for PHS II participants) was defined as new baseline for this analysis. At this time point, 24505 men were still in active follow-up. We excluded 1579 men with missing RLS questionnaire information and 3744 men with CVD events and angina prior to the RLS assessment, leaving a total of 19182 men free of angina and CVD at our defined baseline for our analysis.

All participants of the WHS and the PHS provided written informed consent, and the institutional review board of Brigham and Women's Hospital, Boston, MA, approved the studies as well as the analyses presented here.

\section{Assessment of RLS}

RLS is diagnosed by presence of specific symptoms, and the diagnostic criteria have been established by the International Restless Legs Study Group (IRLSSG). We have implemented standardised questions in both cohorts addressing the four minimal diagnostic criteria of the IRLSSG. Participants were asked: "Do you have unpleasant leg sensations (like crawling, paraesthesias or pain) combined with a motor restlessness and an urge to move?", "Do these symptoms occur only at rest and does moving improve them?", "Are these symptoms worse in the evening or at night compared with the morning?" Participants who answered yes to all the three questions were defined as having RLS. This questionnaire has been established $^{20-22}$ and validated ${ }^{23}$ in previous studies from 
Germany and Italy. Comparing the questionnaire-based diagnosis of RLS with a physician's diagnosis as a gold standard showed good agreement (unweighted $\kappa=0.67$, $\mathrm{p}<0.001){ }^{23}$

\section{Outcome ascertainment}

Participants of both cohorts were asked to report the occurrence of cardiovascular events including myocardial infarction and stroke during follow-up. In addition, information on coronary revascularisation procedures (bypass surgery and percutaneous coronary angioplasty) was collected. Medical records were obtained for all cardiovascular events including coronary revascularisation in the WHS and for all cardiovascular events, but not for coronary revascularisation, in the PHS and were reviewed by an end points committee of physicians. The occurrence of myocardial infarction was confirmed if symptoms met WHO criteria and if the event was associated with abnormal levels of cardiac enzymes or diagnostic ECG. Non-fatal stroke was confirmed if the participant had a new focal neurological deficit of sudden onset and vascular origin that persisted for more than $24 \mathrm{~h}$. Stroke was classified into its major subtypes based on available clinical and diagnostic test information, including brain scans with excellent inter-rater agreement. ${ }^{24} 25$ Cardiovascular deaths were confirmed by reviews of autopsy reports, death certificates, medical records and information obtained from next of kin or other family members. Major CVD was defined as a combined end point of non-fatal stroke, non-fatal myocardial infarction or death from CVD events.

\section{Statistical analysis}

We analysed the association between RLS and incident CVD separately in both studies. Baseline characteristics were compared with respect to RLS status using the t-test for continuous and the $\chi^{2}$ test for categorical variables.

Person-time was calculated from the return date of the questionnaire containing the RLS questions (baseline for this study) to the date of first incident CVD event, non-CVD death, last documented contact or end of the study, whatever occurred first. Information on cardiovascular risk factors and other covariates was updated from the start of the cohorts until the assessment of RLS.

Cox proportional hazards models were used to evaluate the association between RLS and the various CVD events. We calculated age- and multivariable-adjusted HRs and their corresponding 95\% CIs. The multivariable-adjusted models accounted for age, randomised aspirin assignments, history of hypertension (yes/no) history of diabetes (yes/no), history of cholesterol level $\geq 240 \mathrm{mg} / \mathrm{dl}$ (yes/no), parental history of myocardial infarction before the age of 60 years (yes/no), alcohol consumption (rarely/never, 1-3/month, 1-6/week, $\geq 1 /$ day), smoking status (never, past, current), body mass index (BMI) $\left(<25,25-29.9, \geq 30 \mathrm{~kg} / \mathrm{m}^{2}\right)$, exercise (WHS: rarely/never, <1/week, 1-3/week, $\geq 4$ / week; PHS: rarely/never, $\leq 1 /$ week, 2-4/week, 5-7/ week), history of migraine (yes/no) and post- menopausal hormone use (WHS: never, past, current). Additional adjustment for race, geographic location, depression, iron supplementation use, Parkinson's disease, snoring (PHS only), sleep duration (PHS only), fatigue (WHS only), number of pregnancies (WHS only), age at menarche (WHS only), postmenopausal status (WHS only), oral contraceptive use (WHS only) and analgesic use including aspirin, non-steroidal antiinflammatory drugs, acetaminophen (WHS only) and aspirin containing drugs (WHS only) did not change the effect estimate of RLS on any CVD event by more than $10 \%$.

A missing value indicator was incorporated in the outcome models for covariates if the number of participants with missing information was $\geq 100$. We assigned participants with missing values to the covariate reference category if the number of missing information was $<100$. No covariate in the primary analysis had more than $4 \%$ missing.

We evaluated effect modification by age $(<60,60-<70$, $70-<80, \geq 80$ years), iron supplementation use (yes/no), BMI $\left(<25 \mathrm{~kg} / \mathrm{m}^{2}, 25-29.9 \mathrm{~kg} / \mathrm{m}^{2}, \geq 30 \mathrm{~kg} / \mathrm{m}^{2}\right)$, smoking status (never, past, current), history of hypertension (yes/no), fatigue (WHS only) and number of pregnancies (WHS only). Effect modification was tested by including an interaction term for RLS and the potential effect modifier to the outcome model.

The proportional hazards assumption was tested by including an interaction term for RLS status and logarithm of follow-up time for major CVD in age-adjusted models. We found no statistically significant violation.

We performed a sensitivity analysis by excluding participants with a history of polyneuropathy, kidney disease, liver disease, liver cirrhosis (PHS only), rheumatoid arthritis, intermittent claudication and participants who underwent peripheral artery disease surgery. The information on these covariates was updated from the start of the cohorts until assessment of the questionnaire addressing RLS.

For all analyses, we used SAS (V.9.1.3, SAS Institute Inc.). All $\mathrm{p}$ values were two tailed, and $\mathrm{p}<0.05$ was considered statistically significant.

\section{RESULTS}

\section{Baseline characteristics}

The baseline characteristics of participants according to RLS status are presented in table 1 for the WHS and in table 2 for the PHS. The prevalence for RLS was $11.7 \%$ among women and $7.2 \%$ among men. In contrast to the WHS, we observed an age difference according to RLS status in the PHS. Men with RLS had a mean age of 67.8 years and were older than men without RLS. Compared with participants without RLS, both male and female RLS sufferers were more likely to report a history of hypertension, a history of diabetes and a history of hypercholesterolaemia. With regard to lifestyle factors, participants with RLS were more likely to have a BMI $\geq 30 \mathrm{~kg} / \mathrm{m}^{2}$, to rarely/never drink and to rarely/never 
Table 1 Baseline characteristics according to RLS status in the WHS ( $n=29756)$

\begin{tabular}{|c|c|c|c|}
\hline & No RLS ( $n=26269)$ & RLS ( $n=3487)$ & p Value \\
\hline Mean age, years (SD) & $63.4(6.9)$ & $63.3(6.8)$ & 0.30 \\
\hline White & $24786(95.1)$ & $3376(97.4)$ & $<0.01$ \\
\hline Geographic location, n (\%) & & & $<0.01$ \\
\hline Northeast & $5168(19.7)$ & $605(17.4)$ & \\
\hline West & $5713(21.8)$ & 742 (21.3) & \\
\hline \multicolumn{4}{|l|}{ CVD risk factors, $\mathrm{n}(\%)$} \\
\hline History of hypertension & $12273(46.7)$ & $1759(50.4)$ & $<0.01$ \\
\hline History of diabetes & $1709(6.5)$ & $295(8.5)$ & $<0.01$ \\
\hline History of cholesterol $\geq 240 \mathrm{mg} / \mathrm{dl}$ & $13850(52.8)$ & $2013(57.8)$ & $<0.01$ \\
\hline Smoking status & & & $<0.01$ \\
\hline Never & $13484(52.0)$ & $1619(47.0)$ & \\
\hline Past & $10352(39.9)$ & $1504(43.7)$ & \\
\hline Current & $2083(8.0)$ & $321(9.3)$ & \\
\hline Alcohol consumption & & & 0.05 \\
\hline Rarely/never & $11071(42.4)$ & $1558(44.9)$ & \\
\hline $1-3$ drinks per month & $3044(11.7)$ & 394 (11.3) & \\
\hline $1-6$ drinks per week & 8969 (34.4) & $1138(32.8)$ & \\
\hline$\geq 1$ drink/day & 2936 (11.2) & $314(9.0)$ & \\
\hline Exercise & & & $<0.01$ \\
\hline Rarely/never & $9875(37.6)$ & $1380(39.6)$ & \\
\hline Unclear/subject unsure & $264(1.0)$ & $33(0.96)$ & \\
\hline Postmenopausal hormone use & & & $<0.01$ \\
\hline Never & $5626(22.3)$ & $636(18.9)$ & \\
\hline Past & 6347 (25.2) & 836 (24.9) & \\
\hline Current & $13225(52.5)$ & $1891(56.2)$ & \\
\hline \multicolumn{4}{|l|}{ Other covariates, $\mathrm{n}(\%)$} \\
\hline History of migraine & $5509(21.0)$ & $909(26.1)$ & $<0.01$ \\
\hline History of depression & 3132 (11.9) & 707 (20.3) & $<0.01$ \\
\hline History of Parkinson's disease & $105(0.4)$ & $21(0.6)$ & 0.08 \\
\hline Iron supplementation use & $1028(4.0)$ & $124(3.6)$ & 0.30 \\
\hline Being fatigued & $9101(34.8)$ & $1776(51.1)$ & $<0.01$ \\
\hline
\end{tabular}

exercise in both cohorts. In addition, both male and female RLS sufferers more frequently reported a history of depression and migraine.

\section{Risk of CVD}

Women's Health Study

A total of 450 first major CVD events, 176 myocardial infarctions, 245 strokes, 66 CVD deaths and 461 coronary revascularisations were confirmed during a mean follow-up of 6.0 years. Age- and multivariable-adjusted HRs $(95 \%$ CI) for the association between RLS and the various vascular events are presented in table 3 . Women with RLS had an increased age-adjusted HR of 1.42 (1.10 to 1.82 ) for coronary revascularisation. The association was diminished and became insignificant after adjustment for vascular risk factors. RLS was not associated with a significantly increased risk for major CVD, myocardial infarction, stroke or CVD death. 
Table 2 Baseline characteristics according to RLS status in the PHS $(n=19182)$

\begin{tabular}{|c|c|c|c|}
\hline & No RLS ( $n=17809)$ & RLS (n=1373) & p Value \\
\hline \multicolumn{4}{|l|}{ Demographic information } \\
\hline Mean age, years (SD) & $66.6(8.7)$ & $67.8(8.9)$ & $<0.01$ \\
\hline \multicolumn{4}{|l|}{ Ethnicity, n (\%) } \\
\hline White & $16091(90.8)$ & $1288(94.2)$ & $<0.01$ \\
\hline Geographic location, n (\%) & & & 0.16 \\
\hline Northeast & $3983(22.4)$ & $299(21.8)$ & \\
\hline Southeast & $5137(28.8)$ & $359(26.2)$ & \\
\hline Midwest & 4547 (25.5) & $375(27.3)$ & \\
\hline West & $4031(22.6)$ & $329(24.0)$ & \\
\hline Other & $111(0.6)$ & $11(0.8)$ & \\
\hline \multicolumn{4}{|l|}{ CVD risk factors, $\mathrm{n}(\%)$} \\
\hline History of hypertension & 8596 (48.3) & 703 (51.2) & 0.04 \\
\hline History of diabetes & $1200(6.7)$ & $138(10.1)$ & $<0.01$ \\
\hline History of cholesterol $\geq 240 \mathrm{mg} / \mathrm{dl}$ & $8387(47.1)$ & $686(50.0)$ & 0.04 \\
\hline BMI categories $\left(\mathrm{kg} / \mathrm{m}^{2}\right)$ & & & $<0.01$ \\
\hline$<25$ & $7550(42.5)$ & $519(37.8)$ & \\
\hline $25-29.9$ & 8197 (46.1) & $665(48.5)$ & \\
\hline$\geq 30$ & 2038 (11.5) & 189 (13.8) & \\
\hline Smoking status & & & 0.17 \\
\hline Never & $9763(54.9)$ & $719(52.4)$ & \\
\hline Past & 7543 (42.4) & $617(45.0)$ & \\
\hline Current & $495(2.8)$ & $37(2.7)$ & \\
\hline Alcohol consumption & & & $<0.01$ \\
\hline Rarely/never & $3120(17.5)$ & $292(21.3)$ & \\
\hline $1-3$ times/month & $2171(12.2)$ & $157(11.4)$ & \\
\hline $1-6$ times/week & 6631 (37.3) & $514(37.4)$ & \\
\hline$\geq 1$ times/day & $5862(33.0)$ & $410(29.9)$ & \\
\hline Exercise & & & $<0.01$ \\
\hline Rarely/never & $6174(34.8)$ & $536(39.2)$ & \\
\hline$\leq 1 /$ week & $455(2.6)$ & $39(2.9)$ & \\
\hline 2-4 times/week & $7917(44.6)$ & $594(43.4)$ & \\
\hline $5-7$ times/week & $3204(18.1)$ & $200(14.6)$ & \\
\hline Parental history of myocardial infarction & $1910(10.7)$ & $137(10.0)$ & 0.39 \\
\hline \multicolumn{4}{|l|}{ Other covariates, $\mathrm{n}(\%)$} \\
\hline History of migraine & $2157(12.1)$ & $202(14.7)$ & $<0.01$ \\
\hline History of depression & $1709(9.8)$ & $219(16.1)$ & $<0.01$ \\
\hline History of Parkinson's disease & 207 (1.2) & $20(1.5)$ & 0.33 \\
\hline Iron supplementation use & $298(1.9)$ & $25(2.1)$ & 0.73 \\
\hline Sleep duration $\geq 8 \mathrm{~h}$ & $5254(32.7)$ & $431(34.9)$ & 0.11 \\
\hline Snoring & & & 0.24 \\
\hline Never & $4382(26.9)$ & $338(27.0)$ & \\
\hline A few nights & 6604 (40.6) & $482(38.5)$ & \\
\hline Most nights & $5283(32.5)$ & $433(34.6)$ & \\
\hline
\end{tabular}

\section{Physicians' Health Study}

In table 4, age- and multivariable-adjusted HRs (95\% CI) for the association between RLS and vascular outcomes in the PHS are summarised. During a mean follow-up of 7.3 years, 1064 major CVD events, 431 myocardial infarctions, 381 strokes and 389 CVD deaths were confirmed. In addition, 1352 coronary revascularisations were reported. RLS at baseline was not associated with incident vascular events in age-adjusted or multivariable-adjusted models.

\section{Sensitivity analyses}

After excluding participants with comorbid conditions that have been associated with RLS, the lack of associa- tion between RLS and our outcome events remained robust, with the exception of stroke in the WHS. The multivariable-adjusted HR increased from 1.29 (0.91 to 1.82 ) to 1.42 (0.99 to 2.05 ).

In both cohorts, the effect estimates did not change by more than $5 \%$ when excluding a history of diabetes from the list of confounding factors in multivariable-adjusted models.

\section{Effect modification}

The associations between RLS and major CVD were not significantly modified by age ( $\mathrm{p}$ for interaction in the WHS: $0.12, \mathrm{p}$ for interaction in the PHS: 0.51 ), BMI ( $\mathrm{p}$ 
Table 3 Age- and multivariable-adjusted HRs for incident vascular events according to RLS status in the WHS

\begin{tabular}{|c|c|c|c|c|}
\hline & \multicolumn{2}{|c|}{ Primary analysis $(n=29756)$} & \multicolumn{2}{|c|}{ Sensitivity analysis* $(n=27649)$} \\
\hline & $\begin{array}{l}\text { No RLS } \\
\text { history } \\
(n=26269)\end{array}$ & $\begin{array}{l}\text { Any history of RLS } \\
(\mathrm{n}=3487) \\
\mathrm{HR}(95 \% \mathrm{Cl})\end{array}$ & $\begin{array}{l}\text { No RLS } \\
\text { history } \\
(n=24472)\end{array}$ & $\begin{array}{l}\text { Any history of RLS } \\
(n=3177) \\
\text { HR }(95 \% \mathrm{Cl})\end{array}$ \\
\hline Major cardiovascular event & $\mathrm{n}=386$ & $\mathrm{n}=64$ & $n=338$ & $\mathrm{n}=56$ \\
\hline Age adjusted & 1.00 & $1.25(0.96$ to 1.63$)$ & 1.00 & $1.27(0.96$ to 1.69$)$ \\
\hline Multivariable adjusted $\dagger$ & 1.00 & $1.15(0.88$ to 1.50$)$ & 1.00 & $1.18(0.89$ to 1.57$)$ \\
\hline Any stroke & $\mathrm{n}=207$ & $\mathrm{n}=38$ & $\mathrm{n}=178$ & $\mathrm{n}=35$ \\
\hline Age adjusted & 1.00 & $1.39(0.98$ to 1.96$)$ & 1.00 & 1.51 (1.05 to 2.16$)$ \\
\hline Multivariable adjusted $\dagger$ & 1.00 & 1.29 (0.91 to 1.82$)$ & 1.00 & 1.42 (0.99 to 2.05$)$ \\
\hline Myocardial infarction & $n=153$ & $\mathrm{n}=23$ & $n=138$ & $\mathrm{n}=20$ \\
\hline Age adjusted & 1.00 & $1.13(0.73$ to 1.75$)$ & 1.00 & $1.11(0.69$ to 1.77$)$ \\
\hline Multivariable adjusted $\dagger$ & 1.00 & 1.01 (0.65 to 1.57$)$ & 1.00 & $1.00(0.62$ to 1.59$)$ \\
\hline Coronary revascularisation & $n=388$ & $\mathrm{n}=73$ & $n=346$ & $\mathrm{n}=59$ \\
\hline Age adjusted & 1.00 & $1.42(1.10$ to 1.82$)$ & 1.00 & 1.30 (0.99 to 1.72$)$ \\
\hline Multivariable adjusted $\dagger$ & 1.00 & 1.24 (0.96 to 1.59$)$ & 1.00 & $1.14(0.86$ to 1.50$)$ \\
\hline CVD death & $n=57$ & $\mathrm{n}=9$ & $n=52$ & $n=6$ \\
\hline Age adjusted & 1.00 & $1.21(0.60$ to 2.45$)$ & 1.00 & 0.90 (0.39 to 2.09$)$ \\
\hline Multivariable adjusted $\dagger$ & 1.00 & $1.11(0.55$ to 2.25$)$ & 1.00 & 0.85 (0.36 to 1.98$)$ \\
\hline
\end{tabular}

for interaction in the WHS: 0.72, $\mathrm{p}$ for interaction in the PHS: 0.28 ), smoking status ( $p$ for interaction in the WHS: 0.71 , p for interaction in the PHS: 0.43), iron supplementation use ( $p$ for interaction in the WHS: 0.75, $\mathrm{p}$ for interaction in the PHS: 0.35), history of hypertension ( $\mathrm{p}$ for interaction in the WHS: 0.76, $\mathrm{p}$ for interaction in the PHS: 0.43 ), fatigue ( $p$ for interaction
WHS: 0.91) or number of pregnancies ( $\mathrm{p}$ for interaction WHS: 0.92).

\section{DISCUSSION}

In this study, evaluating data from two large prospective cohort studies of women and men, RLS was not associated with an increased risk for incident vascular events

Table 4 Age- and multivariable-adjusted HRs for incident vascular events according to RLS status in the PHS

\begin{tabular}{|c|c|c|c|c|}
\hline & \multicolumn{2}{|c|}{ Primary analysis $(n=19182)$} & \multicolumn{2}{|c|}{ Sensitivity analysis* $(n=15625)$} \\
\hline & $\begin{array}{l}\text { No RLS } \\
\text { history } \\
(n=17809)\end{array}$ & $\begin{array}{l}\text { Any history of RLS } \\
(n=1373) \\
\text { HR }(95 \% \mathrm{Cl})\end{array}$ & $\begin{array}{l}\text { No RLS } \\
\text { history } \\
(n=14578)\end{array}$ & $\begin{array}{l}\text { Any history of RLS } \\
(n=1047) \\
\text { HR }(95 \% \mathrm{Cl})\end{array}$ \\
\hline Major cardiovascular event & $\mathrm{n}=974$ & $\mathrm{n}=90$ & $\mathrm{n}=755$ & $\mathrm{n}=61$ \\
\hline Age adjusted & 1.00 & $1.09(0.88$ to 1.35$)$ & 1.00 & $1.03(0.79$ to 1.33$)$ \\
\hline Multivariable adjusted $\dagger$ & 1.00 & $1.01(0.81$ to 1.25$)$ & 1.00 & $0.96(0.74$ to 1.25$)$ \\
\hline Any stroke & $\mathrm{n}=357$ & $\mathrm{n}=24$ & $\mathrm{n}=271$ & $\mathrm{n}=18$ \\
\hline Age adjusted & 1.00 & $0.77(0.51$ to 1.17$)$ & 1.00 & $0.82(0.51$ to 1.33$)$ \\
\hline Multivariable adjusted $\dagger$ & 1.00 & $0.73(0.48$ to 1.11$)$ & 1.00 & 0.79 (0.49 to 1.28$)$ \\
\hline Myocardial infarction & $n=392$ & $n=39$ & $\mathrm{n}=315$ & $n=25$ \\
\hline Age adjusted & 1.00 & $1.23(0.88$ to 1.71$)$ & 1.00 & $1.06(0.70$ to 1.59$)$ \\
\hline Multivariable adjusted $\dagger$ & 1.00 & $1.12(0.80$ to 1.55$)$ & 1.00 & $0.97(0.64$ to 1.45$)$ \\
\hline Coronary revascularisation & $n=1239$ & $\mathrm{n}=113$ & $\mathrm{n}=976$ & $\mathrm{n}=87$ \\
\hline Age adjusted & 1.00 & $1.15(0.95$ to 1.40$)$ & 1.00 & $1.22(0.98$ to 1.52$)$ \\
\hline Multivariable adjusted $\dagger$ & 1.00 & $1.06(0.88$ to 1.29$)$ & 1.00 & $1.12(0.90$ to 1.40$)$ \\
\hline CVD death & $n=350$ & $n=39$ & $\mathrm{n}=260$ & $\mathrm{n}=25$ \\
\hline Age adjusted & 1.00 & $1.27(0.91$ to 1.77$)$ & 1.00 & $1.17(0.78$ to 1.77$)$ \\
\hline Multivariable adjusted $\dagger$ & 1.00 & $1.22(0.87$ to 1.70$)$ & 1.00 & $1.13(0.75$ to 1.70$)$ \\
\hline
\end{tabular}


including major CVD, myocardial infarction, stroke, coronary revascularisation and CVD death. Excluding participants with comorbidities that have been associated with RLS did not substantially change our results.

\section{Comparison with other studies}

In contrast to our results, findings from several crosssectional studies have suggested a relationship between RLS and prevalent CVD. ${ }^{6-12}$ Among the 3422 participants of the Sleep Heart Health Study, those with RLS had multivariable-adjusted OR (95\% CIs) of 2.05 (1.38 to 3.04) for CVD and 2.07 (1.43 to 3.00) for coronary artery disease. Winkelman $e t a l^{12}$ additionally report an association between severity and frequency of RLS and CVD. Compared with those without RLS, participants who reported a RLS frequency of $16-23 /$ month had an OR of 3.53 (1.85 to 6.76) for CVD. Duration of disease was not related to CVD. In our cohorts, data on frequency and severity of symptoms were not available and we had no information about the duration of disease.

Two studies from Sweden, one analysing a random sample of the female population of central Sweden aged 18-64 years and the other one evaluating a comparable random sample of men with the same age range, report an association between RLS and self-reported heart disease. ${ }^{9}{ }^{10}$ As in our study, RLS was defined according to IRLSSG diagnostic criteria in these studies and the observed overall prevalences were comparable to those in our cohorts. The multivariable-adjusted OR for heart disease was 2.13 (1.18 to 3.86) in the female Swedish cohort and 2.5 (1.4 to 4.3 ) in the study evaluating the random sample of Swedish men.

In the Caerphilly cohort of 1986 men, RLS was associated with incident stroke (multivariable-adjusted OR of 1.67 (1.07 to 2.06)). In addition, the authors report an increased but not significant OR of 1.24 (0.89 to 1.74) for incident ischaemic heart disease events. While we do not find an association between RLS and stroke in out main analysis, the sensitivity analysis suggests potential increased risk for stroke (RR 1.42 (0.99 to 2.05)). RLS was not defined according to IRLSSG diagnostic criteria and the associations were not adjusted for important vascular risk factors including hypertension and diabetes, which are potential limitations of this study. ${ }^{13}$

One cross-sectional study using data from the Burden of Obstructive Lung Disease Initiative in Iceland and Sweden is in line with our finding. ${ }^{26}$ A random sample of adults aged 40 years and older was drawn from the national registries in both countries. Benediktsdottir et al found a significant higher prevalence of RLS in Icelandic women compared with those from Sweden. In multivariable-adjusted models, RLS, defined according to IRLSSG criteria, was not associated with CVD, assessed by a structured interview, in this study.

A high percentage of RLS patients report periodic limb movements during sleep (PLMS), and PLMS are considered as supportive clinical feature of RLS. ${ }^{27}$ The association between periodic limb movements and inci- dent CVD has been recently evaluated among 2911 men aged $\geq 65$ years who participated in the Outcomes of Sleep Disorders in Older Men Sleep Study. ${ }^{28}$ Periodic limb movements were assessed by two indices, the periodic limb movement index and the periodic limb movement arousal index. After 4.4 years of mean followup, men with a periodic limb movement arousal index $\geq 5$ had a multivariable-adjusted HR of 1.26 (1.01 to 1.56) for all-cause CVD compared with those with the lowest index category. The periodic limb movement index was not statistically significant associated with allcause CVD (HR 1.25, 95\% CI 1.00 to 1.56 ), which was defined as a composite end point of coronary heart disease, cerebrovascular disease and peripheral artery disease. When evaluating the different end points separately, incident peripheral artery disease was the only CVD event that was significantly associated with one of the indices in multivariable-adjusted models (HR 2.00, 95\% CI 1.14 to 3.49 ). Although PLMS is frequently reported by RLS sufferers, it is not exclusively related to RLS and occurs in other sleep-related disorders and medical conditions. Since the frequency of RLS sufferers could not be determined in the previous mentioned study, the results cannot be translated to a RLS population and the comparability of these results to our study is limited.

RLS can be distinguished in idiopathic and secondary forms. A variety of disorders have been identified to be associated with secondary RLS including anaemia, iron deficiency, rheumatoid arthritis, polyneuropathies and reduced renal function. La Manna et al evaluated the association between RLS and incident CVD events among 100 end-stage kidney disease patients who were on dialysis three times a week. ${ }^{29}$ After 18 months of follow-up, patients with secondary RLS had an increased risk for CVD events (myocardial infarction, stroke or peripheral artery occlusion), which, however, did not reach statistical significance. In addition, patients with RLS had higher fibrinogen levels, albumin levels, white blood cell counts and higher overall mortality, suggesting that RLS status could be an indicator for poorer health status. Since the study analysed a very distinct population, the comparability of these results with studies in healthier populations including ours is limited.

A possible explanation for the discrepancy between our results and those of previous studies is the prospective cohort design, which allows the assessment of incident CVD cases. Thus, while RLS does not seem to be a risk factor for subsequent CVD, it might be an indicator of a poor health status due to the presence of several, especially cardiovascular, comorbidities.

\section{Strengths and limitations}

Our study has several strengths including the large number of participants in both cohorts, large number of outcome events, prospective design and standardised assessment of RLS according to the four minimal diagnostic criteria of the IRLSSG. Furthermore, incident 
CVD events were confirmed by medical record review. In addition, information on many comorbidities and lifestyle factors was available allowing us to adjust for potential confounders.

The following limitations should be considered when interpreting our results. First, information on RLS was self-reported and potential misclassification is possible. However, the questionnaire has been successfully used and validated in previous cohorts from Germany and Italy, and the prevalences of RLS in both cohorts are similar to those reported in other population-based studies. ${ }^{1}$ Furthermore, both cohorts consist of health professionals and previous studies indicate that participants with a health profession accurately report information. ${ }^{30}$ Moreover, we have excluded participants with comorbidities potentially mimicking RLS syndromes in sensitivity analysis and the results were largely unchanged. Second, we had no information on frequency, severity and duration of RLS symptoms. Third, residual and unmeasurable confounding remains possible as our study is observational. However, we are not aware of any factor that, if controlled for, would establish an association between RLS and CVD. Fourth, both of our cohorts consist of predominately white health professionals, which may limit generalisability to other populations. However, we have no reason to believe that potential biological associations between RLS and CVD are different in our compared with other populations.

\section{Clinical implications}

Results of these two large prospective studies do not suggest that RLS is a marker for increased risk of CVD independent of other cardiovascular risk factors. However, our data also indicate that the prevalence of RLS increases with several comorbidities including traditional CVD risk factors like BMI, hypertension and diabetes. Therefore, patients diagnosed with RLS should be carefully screened for relevant comorbidities and subsequently treated.

\section{Unanswered questions and future research}

RLS is a complex disease and the mechanisms underlying the disease have not been fully understood yet. Understanding the role of diverse comorbidities for the onset of RLS would be an important research target for the future in order to establish strategies to prevent the disease.

\footnotetext{
Author affiliations

${ }^{1}$ Division of Preventive Medicine, Department of Medicine, Brigham and Women's Hospital, Harvard Medical School, Boston, Massachusetts, USA ${ }^{2}$ Department of Neurology, University Hospital of Essen, Essen, Germany ${ }^{3}$ Institute of Epidemiology and Social Medicine, University of Münster, Münster, Germany

${ }^{4}$ INSERM Unit 708 - Neuroepidemiology, Bordeaux, France

${ }^{5}$ University of Bordeaux, Bordeaux, France

Author footnote

Access to data: All authors had full access to all the data in the study and can take responsibility for the integrity of the data and accuracy of the data analyses.
}

We report a full disclosure for the last 3 years for each author: ACW has received an international postdoctoral research fellowship of the American Association of University Women and a research fellowship of the German Research Foundation. MS has received an investigator-initiated research grant from the Migraine Research Foundation. He has received honoraria from L.E.K. Consulting for telephone surveys and from the American Academy of Neurology for educational material. Since August 2011, he is full-time employee of Bayer HealthCare Deutschland Pharmaceuticals. RJG has received investigator-initiated research funding and support from the National Institutes of Health, AstraZeneca, and Novartis and has received honoraria from Merck for lectures. JEB has received investigator-initiated research funding and support from the National Institutes of Health and Dow Corning Corporation; research support for pills and/or packaging from Bayer Healthcare and the Natural Source Vitamin E Association. JMG has received investigator-initiated research funding and support as Principal Investigator from the National Institutes of Health, BASF, DSM Pharmaceuticals, Wyeth Pharmaceuticals, McNeil Consumer Products and Pliva, received honoraria from Bayer and Pfizer for speaking engagements and is a consultant for Bayer, McNeil Consumer Products, Wyeth Pharmaceuticals, Merck, Nutraquest and GlaxoSmithKline. KB has received research support for the conduction of DMKG Headache Study unrestricted grants of equal share from the German Migraine and Headache Society and a consortium formed by Allmiral, Astra-Zeneca, Berlin-Chemie, Boehringer Ingelheim Pharma, Boots Healthcare, GlaxoSmithKline, Janssen Cilag, McNeil Pharmaceuticals, MSD Sharp \& Dohme, Pfizer; for the 'Course of Restless Legs Syndrome Study' unrestricted grants from the German Restless Legs Society and a consortium formed by Boehringer Ingelheim Pharma, Mundipharma Research, Neurobiotec, UCB (Schwarz Pharma) and Roche Pharma; from the German Minister of Research and Education for several research projects within the German Competence Net Stroke and an ongoing cohort study on depression and subclinical arteriosclerosis. TK has received investigator-initiated research funding from the French National Research Agency, the US National Institutes of Health, Merck, the Migraine Research Foundation and the Parkinson's disease Foundation. He is a consultant to World Health Information Science Consultants, LLC, and has received honoraria from the $B M J$ for editorial work, from the American Academy of Neurology and Merck for educational lectures and from MAP Pharmaceutical for contributing to a scientific advisory panel.

Acknowledgements We are indebted to the participants in the WHS and PHS for their outstanding commitment and cooperation and to the entire WHS and PHS staff for their expert and unfailing assistance.

Contributors ACW: study design, data analysis, data interpretation and writing of the first draft of the manuscript. MS: study design and conception, data interpretation and critical revisions of the manuscript draft for important intellectual content. RJG: study design, data interpretation and critical revisions of the manuscript draft for important intellectual content. JEB: data interpretation, obtaining funding and critical revisions of the manuscript draft for important intellectual content. JMG: data interpretation, obtaining funding and critical revisions of the manuscript draft for important intellectual content. KB: study design, data interpretation and critical revisions of the manuscript draft for important intellectual content. TK: study design and conception, data analysis, data interpretation, obtaining funding and critical revisions of the manuscript draft for important intellectual content.

Funding This study was supported by a grant from the National Heart, Lung, and Blood Institute (HL-091880). The Women's Health Study is supported by grants from the National Heart, Lung, and Blood Institute (HL-043851, HL-080467 and HL-099355) and the National Cancer Institute (CA-47988). The Physicians' Health Study is supported by grants from the National Cancer Institute (CA-34944, CA-40360 and CA-097193) and from the National Heart, Lung, and Blood Institute (HL-26490 and HL-34595).

Competing interests None.

Patient consent Obtained.

Ethical approval Ethical approval was approved by the Intuitional Review Board of Brigham and Women's Hospital, Boston (Protocol \#: 2008-P-000613/3), MA, and all participants provided written informed consent.

Provenance and peer review Not commissioned; externally peer reviewed 
Data sharing statement No additional data available.

\section{REFERENCES}

1. Berger K, Kurth T. RLS epidemiology - frequencies, risk factors and methods in population studies. Mov Disord 2007;22(Suppl 18): S420-3

2. Innes KE, Selfe TK, Agarwal P. Prevalence of restless legs syndrome in North American and Western European populations: a systematic review. Sleep Med 2011;12:623-34.

3. Paulus W, Dowling P, Rijsman R, et al. Pathophysiological concepts of restless legs syndrome. Mov Disord 2007;22:1451-6.

4. Winkelmann J, Schormair B, Lichtner P, et al. Genome-wide association study of restless legs syndrome identifies common variants in three genomic regions. Nat Genet 2007;39:1000-6.

5. Winkelmann J, Czamara D, Schormair B, et al. Genome-wide association study identifies novel restless legs syndrome susceptibility loci on 2p14 and 16q12.1. PLoS Genet 2011;7:e1002171.

6. Chen NH, Chuang LP, Yang CT, et al. The prevalence of restless legs syndrome in Taiwanese adults. Psychiatry Clin Neurosci 2010;64:170-8.

7. Juuti AK, Laara E, Rajala U, et al. Prevalence and associated factors of restless legs in a 57-year-old urban population in northern Finland. Acta Neurol Scand 2009;122:63-9.

8. Ohayon MM, Roth T. Prevalence of restless legs syndrome and periodic limb movement disorder in the general population. $J$ Psychosom Res 2002;53:547-54.

9. Ulfberg J, Nystrom B, Carter N, et al. Prevalence of restless legs syndrome among men aged 18 to 64 years: an association with somatic disease and neuropsychiatric symptoms. Mov Disord 2001;16:1159-63.

10. Wesstrom J, Nilsson S, Sundstrom-Poromaa I, et al. Restless legs syndrome among women: prevalence, co-morbidity and possible relationship to menopause. Climacteric 2008;11:422-8.

11. Winkelman JW, Finn L, Young T. Prevalence and correlates of restless legs syndrome symptoms in the Wisconsin Sleep Cohort. Sleep Med 2006;7:545-52.

12. Winkelman JW, Shahar E, Sharief I, et al. Association of restless legs syndrome and cardiovascular disease in the Sleep Heart Health Study. Neurology 2008;70:35-42.

13. Elwood P, Hack M, Pickering J, et al. Sleep disturbance, stroke, and heart disease events: evidence from the Caerphilly cohort. $J$ Epidemiol Community Health 2006;60:69-73.

14. Walters AS, Rye DB. Review of the relationship of restless legs syndrome and periodic limb movements in sleep to hypertension, heart disease, and stroke. Sleep 2009;32:589-97.

15. Guggisberg AG, Hess CW, Mathis J. The significance of the sympathetic nervous system in the pathophysiology of periodic leg movements in sleep. Sleep 2007;30:755-66.

16. Final report on the aspirin component of the ongoing Physicians' Health Study. Steering Committee of the Physicians' Health Study Research Group. N Engl J Med 1989;321:129-35.
17. Christen WG, Gaziano JM, Hennekens CH. Design of Physicians' Health Study II-a randomized trial of beta-carotene, vitamins $E$ and $\mathrm{C}$, and multivitamins, in prevention of cancer, cardiovascular disease, and eye disease, and review of results of completed trials. Ann Epidemiol 2000;10:125-34

18. Rexrode KM, Lee IM, Cook NR, et al. Baseline characteristics of participants in the Women's Health Study. J Womens Health Gend Based Med 2000;9:19-27.

19. Ridker PM, Cook NR, Lee IM, et al. A randomized trial of low-dose aspirin in the primary prevention of cardiovascular disease in women. N Engl J Med 2005;352:1293-304.

20. Berger K, Luedemann J, Trenkwalder C, et al. Sex and the risk of restless legs syndrome in the general population. Arch Intern Med 2004;164:196-202.

21. Hogl B, Kiechl S, Willeit J, et al. Restless legs syndrome: a community-based study of prevalence, severity, and risk factors. Neurology 2005;64:1920-4.

22. Rothdach AJ, Trenkwalder C, Haberstock J, et al. Prevalence and risk factors of RLS in an elderly population: the MEMO study. Memory and Morbidity in Augsburg Elderly. Neurology 2000;54:1064-8.

23. Berger $\mathrm{K}$, von Eckardstein A, Trenkwalder C, et al. Iron metabolism and the risk of restless legs syndrome in an elderly general population-the MEMO-Study. J Neurol 2002;249:1195-9.

24. Atiya $\mathrm{M}$, Kurth $\mathrm{T}$, Berger $\mathrm{K}$, et al. Interobserver agreement in the classification of stroke in the Women's Health Study. Stroke 2003;34:565-7.

25. Berger K, Kase CS, Buring JE. Interobserver agreement in the classification of stroke in the physicians' health study. Stroke 1996;27:238-42.

26. Benediktsdottir B, Janson $\mathrm{C}$, Lindberg $\mathrm{E}$, et al. Prevalence of restless legs syndrome among adults in Iceland and Sweden: lung function, comorbidity, ferritin, biomarkers and quality of life. Sleep Med 2010;11:1043-8.

27. Allen RP, Picchietti D, Hening WA, et al. Restless legs syndrome: diagnostic criteria, special considerations, and epidemiology. A report from the restless legs syndrome diagnosis and epidemiology workshop at the National Institutes of Health. Sleep Med 2003; 4:101-19.

28. Koo BB, Blackwell T, Ancoli-Israel S, et al. Association of incident cardiovascular disease with periodic limb movements during sleep in older men: Outcomes of Sleep Disorders in Older Men (MrOS) Study. Circulation 2011;124:1223-31.

29. La Manna G, Pizza F, Persici E, et al. Restless legs syndrome enhances cardiovascular risk and mortality in patients with end-stage kidney disease undergoing long-term haemodialysis treatment. Nephrol Dial Transpl 2011;26:1976-83.

30. Colditz GA, Martin P, Stampfer MJ, et al. Validation of questionnaire information on risk factors and disease outcomes in a prospective cohort study of women. Am J Epidemiol 1986;123:894-900. 